\title{
Morphological and Biochemical Characterization of Bacteria Isolated from Fresh and Salted Hilsa, Tenualosa ilisha (Hamilton, 1822)
}

\author{
Tahara Rohomania ${ }^{1}$, Mihir Lal Saha ${ }^{2}$, Anwar Hossain ${ }^{1}$ and Mohammad Shamsur Rahman ${ }^{1, *}$ \\ ${ }^{1}$ Department of Fisheries, Faculty of Biological Sciences, University of Dhaka, Dhaka-1000, Bangladesh, ${ }^{2}$ Department of Botany, Faculty of \\ Biological Sciences, University of Dhaka, Dhaka-1000, Bangladesh
}

\begin{abstract}
Morphological and biochemical characterization of different bacteria isolated from eight fresh and salted hilsa collected from four fish markets namely Palashi Bazaar, Karwan Bazaar, Anando Bazaar and New Market of Dhaka city was carried out. Five types of bacteriological culture media namely nutrient agar as generalized complex medium, EMB agar medium for coliform, SS agar for Salmonella-Shigella, MSA for Staphylococcus and TCBS for Vibrio were used to isolate the bacteria associated with the hilsa. In salted hilsa, no microbial growth was observed on SS and TCBS agar plate. A total of 66 bacterial isolates were obtained in the study where detail study of 24 strains (12 Gram positive and 12 Gram negative) using morphological and biochemical characterization was conducted. Variable morphological and biochemical properties of the isolated strains were observed. Gram positive bacteria such as Listeria monocytogenes, Bacillus megaterium, B. marinus, Planococcus citreus, Micrococcus varians, M. nishinomiyaensis, Staphylococcus lentus, S. epidermidis, S. aureus and Gram negative bacteria such as Salmonella paratyphi, Salmonella spp., Proteus morganii, P. vulgaris, Vibrio sp., Halobacterium sp. were presumptively identified in the current study. Presence of these bacteria in fish indicates the possibility of occurrence of food poisoning. So, care should be taken during handling and consumption of hilsa whether fresh or salted as it carries pathogenic strains of bacteria of public health concern.
\end{abstract}

Key words: Fresh Hilsa, Salted Hilsa, Bacteria, Strain characterization

\section{Introduction}

As the National fish of Bangladesh, the Indian shad Hilsa (Tenualosa ilisha Hamilton, 1822) is one of the most important tropical fishes in the Indo-Pacific region and has occupied a top position among the edible fishes due to its superb taste, mouth-watering flavour and delicate culinary properties ${ }^{1}$. Most of the hilsa are consumed as fresh but processed through semi-IQF (individual quick freezing), wood-smoking, plain salting and salt fermenting are also consumed. Due to high lipid content, hilsa cannot be sun dried. Therefore, most preferred short term method of preservation is icing and long term one is salting or salt-fermenting. Preservation of hilsa by salt is an old age technology. This method of preservation still enjoys popularity in many developing countries owing to its simplicity and low cost of processing ${ }^{2}$. This way of processing might have been started to quickly preserve large quantity of fish in an inexpensive way. High lipid content makes the hilsa very susceptible to oxidative rancidity, along with rapid autolytic and bacteriological decomposition $^{3}$. Though the spoilage of salted fish is less severe but it is usually contaminated with the harmful bacteria like Bacillus spp., Staphylococcus spp., Micrococcus varians, M. luteus, Pseudomonas mallei and the fungi like Aspergillus niger, A. flavus and Rhizopus spp. ${ }^{4}$. Therefore, the objective of the present study was to isolate and characterize bacterial strains from fresh and salted hilsa based on morphology and biochemical test.

\section{Materials and Methods}

Collection and preparation of sample for microbial analyses Four well known fish markets of Dhaka city namely Palashi Bazaar, Karwan Bazaar, Anando Bazaar and New Market were selected for sampling fresh and salted hilsa. Fish samples were collected aseptically in sterile plastic bags and fresh and salted hilsa were preserved in a refrigerator at $-20^{\circ} \mathrm{C}$ and $4^{\circ} \mathrm{C}$ respectively before microbial analysis. Ten grams of fish muscle from each sample (4 fresh and 4 salted samples) was minced properly and diluted to $90 \mathrm{~mL}$ sterile distilled water in conical flask and shaken well. One milliliter of each of the diluted sample was spread in duplicate over various agar plates (Nutrient agar (NA) for aerobic heterotrophic bacteria, Eosine Methylene Blue (EMB) for coliform bacteria, Salmonella-Shigella (SS agar) for Salmonella and Shigella, Manitol salt agar (MSA) for Staphylococcus and Thiosulphate citrate bile-salt sucrose (TCBS agar) for Vibrio) and incubated at $37^{\circ} \mathrm{C}$ for $24 \mathrm{~h}$.

\section{Isolation of bacteria}

Based on the colony morphology well discrete aerobic heterotrophic, coliform and related enteric bacterial colonies were selected and stocked on slant for further studies. After initial selection on the basis of growth pattern, the selected isolates were purified through repeated plating (by streaking plate technique). The purified isolates were then transferred on NA, EMB, SS agar, MSA and TCBS agar slant. The slants kept in polythene bags and preserved as stock culture in a refrigerator at $4^{\circ} \mathrm{C}$ for further study. Periodical transfers of isolates on agar slants were done for maintaining viability of the organisms.

Morphological observation of isolates

For the identification of selected isolates, Colony morphology such as colony form, elevation, margin, surface, pigmentation, 
opacity, whether grown inside, at the bottom or on the surface of the medium and their rate of growth was studied ${ }^{5,6}$. Bacterial cell suspension using fresh culture was used for Microscopic examination of isolates with simple staining ${ }^{6}$ and differential staining (Gram- and spore- staining) ${ }^{7}$. Wet mount method ${ }^{7}$ was used for the study of vegetative cells, spores, sporangia and motility. Photomicrographs were taken with an advanced research microscope (Nikon Microphot, Japan) fitted with photo micrographic attachment (Nikon, FX 35 WA, Japan).

\section{Physiological and biochemical studies of the isolates}

Following Manual of Microbiological Methods ${ }^{6}$, Understanding Microbes ${ }^{7}$, Bergey's Manual vol. $1^{8}$ and vol. $2^{9}$ and Microbiological Methods ${ }^{10}$ the following important physiological and biochemical tests of the isolated bacteria were carried out viz. Catalase test, Deep glucose agar test Voges-Proskauer (VP) Test, Methyl red test, Hydrolysis of casein, Hydrolysis of starch, Utilization of Citrate, and propionate, Nitrate reduction test, Production of indole, Oxidase test, Kligler's Iron Agar (KIA) test, Motility test by wet mount method, Urease production test, Potassium hydroxide solubility test, Growth response of the isolates at different concentrations of $\mathrm{NaCl}$.

\section{Presumptive identification of the isolates}

Gram positive bacteria were provisionally identified following Bergey's Manual of Systematic Bacteriology ${ }^{9}$. Gram negative, enteric and related bacteria were identified following Bergey's Manual of Systematic Bacteriology ${ }^{8}$ and Manual for Laboratory Investigations of Acute Enteric Infections ${ }^{11}$.

\section{Results and Discussion}

\section{Isolation of the Bacteria}

During this study a total of 66 colonies were primarily selected from different culture media. Among them 24 representative isolates (12 Gram-positive and 12 Gram-negative) were randomly selected for detail study towards identification based on colony morphology, microscopic observation, physiological and biochemical characteristics.

\section{Morphological observation of the isolates}

Colonies of the selected isolates were found to be different in their form, elevation, margin, surface, colour and optical characteristics. Most of the colonies of the isolated bacteria were entire, convex, smooth and off-white in nature. Among the Gram positive bacterial isolates, three were rod shaped and reaming 9 isolates were cocci. On the other hand the Gram negative bacteria were short rod and non- spore former. Photomicrographs of the selected isolates were shown in the Figure $1 \& 2$.
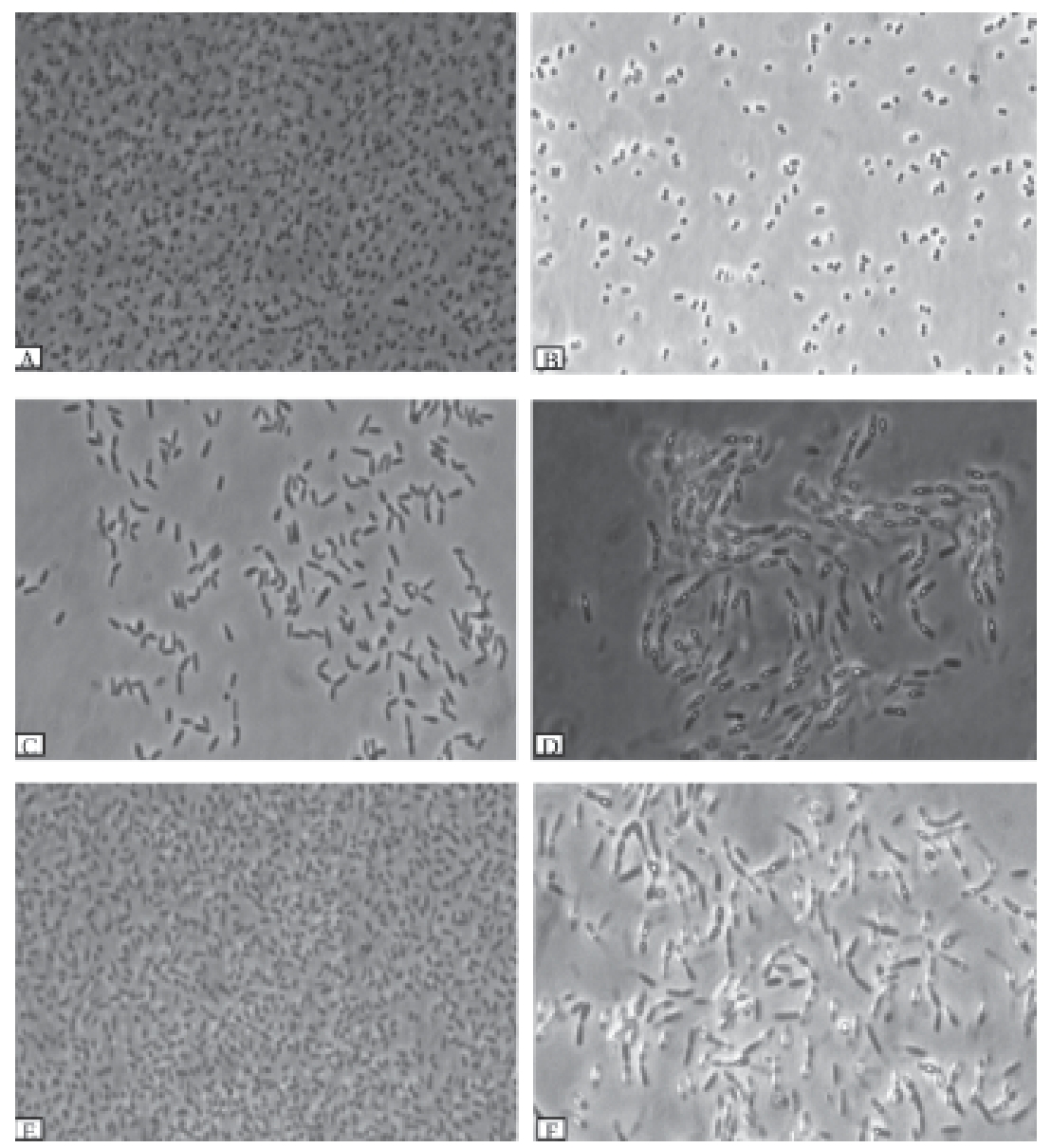

Figure 1. Photomicrographs showing vegetative cells, spores and sporangia of the selected isolates under phase contrast microscope. A. S1/NA/2'/1, B. S2/NA/2/1, C. S4/MSA/2/1, D. S2/NA/3/1, E. S4/TCBS/1 and F. S6/EMB/2/1. Bar = 10ìm. 

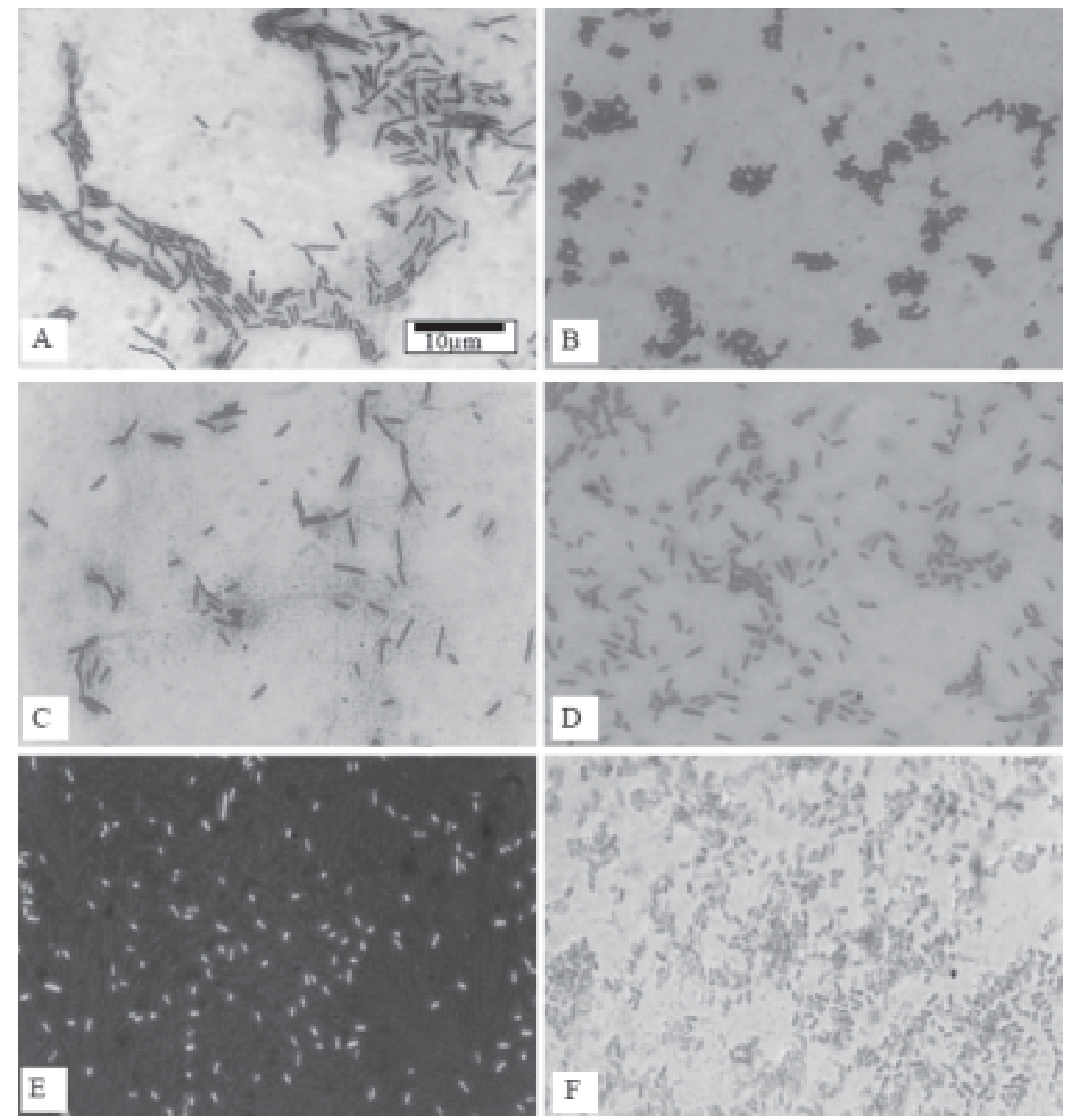

Figure 2. Photomicrographs showing Simple staining of isolate no. A. S2/NA/3/1, B. S4/NA/2/1; Gram staining of C. S1/NA/2'/1 \& D. S4/EMB/1/6; Negative staining of E. S4/TCBS/1 and Spore staining of F. S2/NA/3/1. Bar = 10im.

Physiological and biochemical characteristics of Gram positive bacteria

All the tested isolates were catalase positive. Eight isolates S1/ $\mathrm{NA} / 2^{\prime} / 1, \mathrm{~S} 2 / \mathrm{NA} / 2 / 1, \mathrm{~S} 2 / \mathrm{MSA} / 1 / 1, \mathrm{~S} 3 / \mathrm{MSA} 1^{\prime} / 1, \mathrm{~S} 4 / \mathrm{NA} / 2 / 1, \mathrm{~S} 4 /$ MSA1/1, S5/MSA/1/2 and S6/MSA/2/1 showed growth only at the surface of deep glucose agar medium and thus could be considered as strictly aerobes and other four isolates showed growth throughout the deep glucose agar medium thus could be considered as facultative anaerobes (Table 1). Among 12 Gram positive isolates 7 showed positive results for the VP test and 7 isolates showed positive results for MR test. Out of 12 Gram positive isolates only one isolate (S4/NA/2/1) could produce gas from glucose. In case of casein hydrolysis, four organisms S2/ NA/3/1, S3/EMB/2/1, S/NA/2/1 and S6/NA/1/1 could hydrolyze casein. Only four isolates S2/NA/3/1, S3/EMB/2/1, S3/MSA/1'/1 and $\mathrm{S} 4 / \mathrm{NA} / 2 / 1$ were able to hydrolyze starch. Out of the 12 isolates S2/MSA/1/1, S4/MSA/2/1 and S6/NA/1/1 could not utilize both citrate and propionate; 8 isolates could utilize citrate and propionate. Among the 12 tested organisms, seven could not reduce nitrate.

Physiological and biochemical characteristics of Gram negative bacteria

The results of physiological and biochemical tests presented in Table 2. All the organisms were catalase positive and showed positive result with the $\mathrm{KOH}$ solubility test. Among the 12 tested organisms only 5 isolates S2/EMB/2'/1, S4/SS/2/1, S5/SS/1/2, S5/EMB/1/4 and S6/TCBS1/1 showed negative results in VP test. In case of MR test 6 isolates showed positive results. In the hydrolysis test 2 Gram negative isolates (S3/EMB/2/2 and S4/TCBS/1) showed positive results for casein and starch hydrolysis. Only one isolate (S4/TCBS/1) could produce indole. Out of 12 isolates five were positive to degrade urea. Three isolates (S4/TCBS/1, S5/SS/1/2 and S6/EMB/1'/1) could produce the enzyme oxidase. Only two organisms (S4/SS/2/1 and S5/SS/ $1 / 2$ ) were able to produce $\mathrm{H}_{2} \mathrm{~S}$ in KIA test and 9 organisms produced gas. 


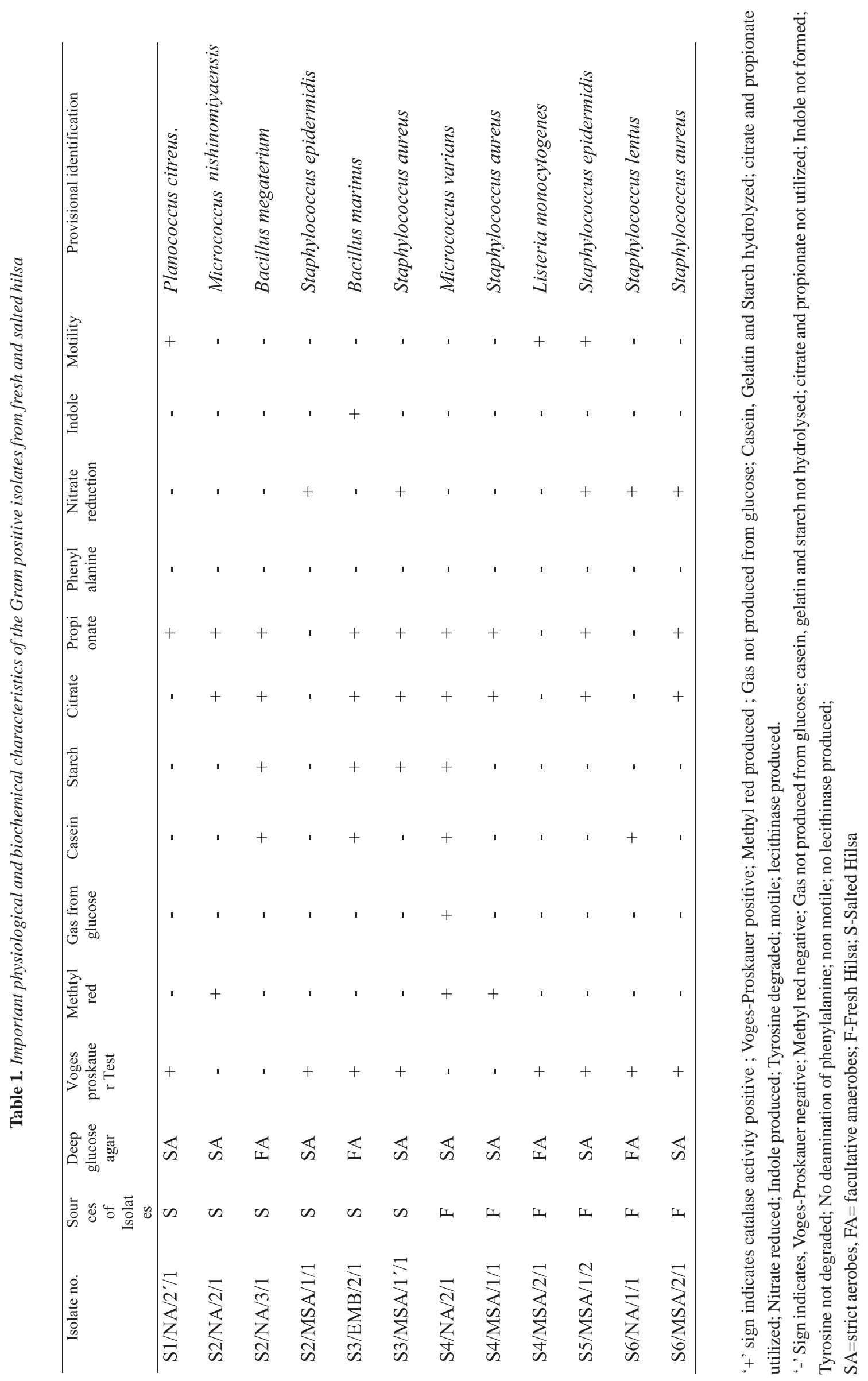




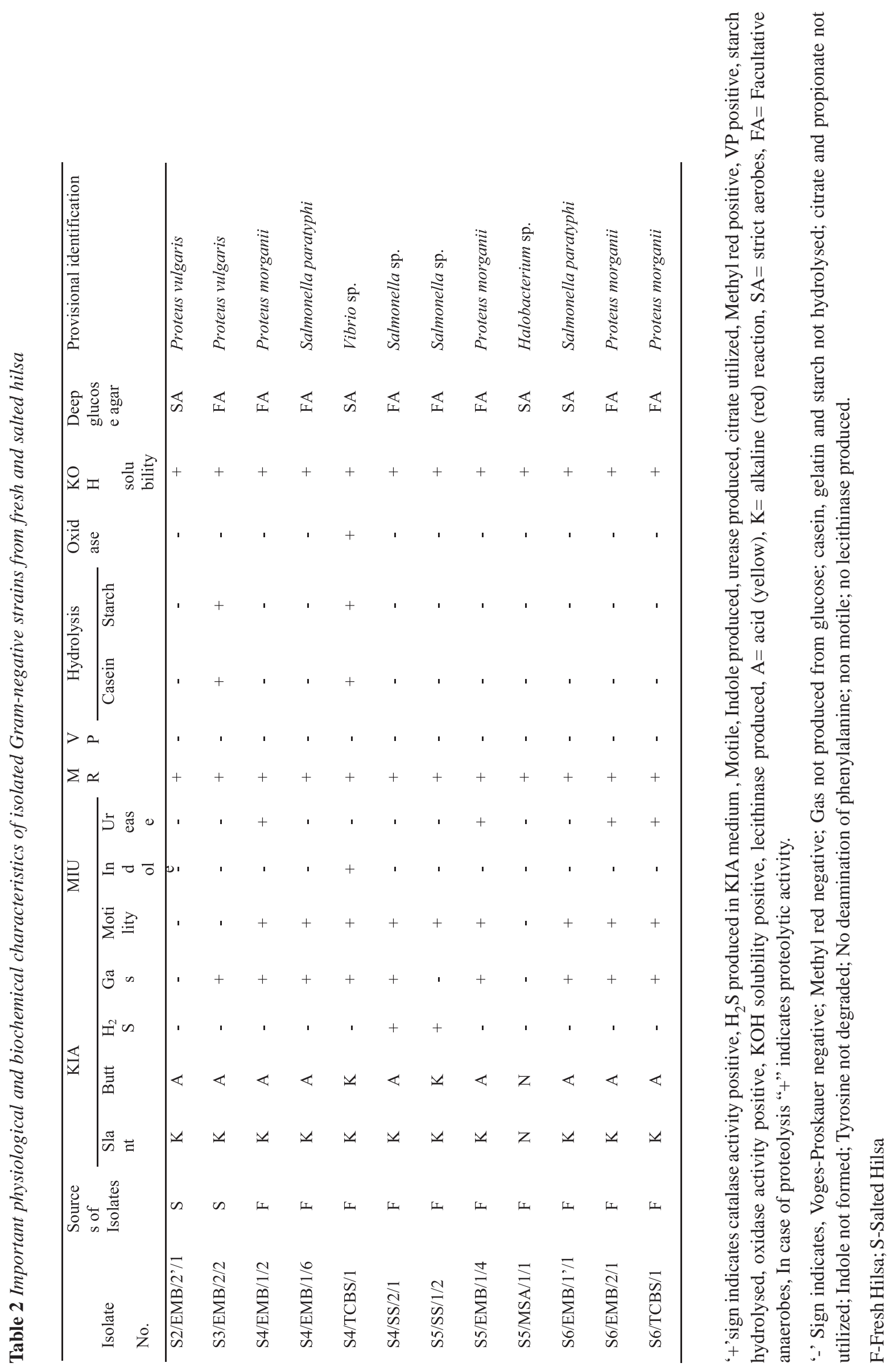




\section{Growth response at different concentrations of $\mathrm{NaCl}$}

Effect of different salt concentrations (2, 4, 6, 8 and 10\%) on the isolated bacteria was observed. The results showed that the organisms had a wide range of tolerance towards $\mathrm{NaCl}$ concentration. The maximum growth of the organisms was found in salt concentration between 2 and 6\%.

\section{Provisional Identification of the isolates}

During this investigation a number of bacteria were isolated and finally 24 were selected for detail study. After thorough characterization ${ }^{(8,9)}$ provisional identification was done on the basis of observed and tested characters of the isolated organisms. The two separate groups (i) Gram positive, aerobic heterotrophic bacteria (ii) Gram-negative enteric and related bacteria were presented in Tables 1 \& 2 .

Among these isolates 12 were members of Gram positive bacteria. Out of these Gram positive members 9 isolates were cocci; among them only one isolate (S1/NA/2×/1) Planococcus, six isolates S2/MSA/1/1, S3/MSA/1'/1, S4/MSA/1/1, S5/MSA/1/2, S6/NA/ $1 / 1$ and S6/MSA/2/1 were the member of Staphylococcus and remaining two isolates were the member of Micrococcus (S2/ NA/2/1 and S4/NA/2/1), respectively. Three isolates of Gram positive bacteria were rod shaped and two spore former of them fell under the genus Bacillus. The identified species were Bacillus megaterium and B. marinus and the remaining Gram positive non spore former rod was the member of Listeria monocytogenes.

In a previous study, Sultana et al., showed that frequently isolated bacteria from salted hilsa collected from local markets of Dhaka city included Staphylococcus aureus, Staphylococcus epidermidis, Bacillus cereus, Bacillus subtilis, Bacillus megaterium, Micrococcus luteus, Micrococcus varians ${ }^{4}$. Presence of Staphylococcus spp. suggests that there was higher level of environmental contaminants and its presence indicates the possible risks of food poisoning as found by Mhlambi et al. ${ }^{12}$. Majumdar et al. found Micrococcus and Bacillus species are main bacterial flora of salt fermented hilsa fish ${ }^{2}$. Mahin et al. identified Staphylococcus aureus, Micrococcus varians, Bacillus subtilis, Bacillus megaterium and Micrococcus radiodurans from fresh water mola fish ${ }^{13}$. During ripening of salted anchovy, PerezVillarreal and Pozo showed that halophilic and halotolerant bacteria like Micrococcaceae, lactic acid bacteria were dominated microflora ${ }^{14}$.

Twelve Gram negative bacterial isolates were belonged to the member of Salmonella paratyphi (2), Salmonella spp. (2), Proteus morganii (4), Proteus vulgaris (2), Vibrio sp. (1) and Halobacterium sp. (1) (Table 2). Proteus morganii were detected both in fresh and salted hilsa. According to Huss ${ }^{15}$, Gram negative bacteria are more dominant over Gram positive bacteria in fish. However this depends on many factors such as fish species, location of fish body from where sample is taken, storage time after dying, habitat of fish etc. Salmonella spp. in aquaculture fish products mainly originates from the environment rather than from poor standards of hygiene and sanitation. But sometimes, incidence of this bacterium in fish, shrimp or similar foods of aquatic habitats may be happened due to external contamination. Most fish are cooked prior to consumption. These products, therefore, cause negligible health risks to the consumers except for cross contamination in the kitchens ${ }^{16}$. Salmonella has been isolated from fresh, frozen, canned and sun dried marine fish products ${ }^{17}$. This bacterium has been isolated from different raw hilsa products in different market of Dhaka city during this study. Vibrio and Salmonella were not found in a study of hilsa and indicated that these bacterium could survive less than that of other bacteria associated with the hilsa ${ }^{18}$. In the present study Vibrio was present in fresh hilsa and it might be due to contamination during handling in the market. Presence of coliform bacteria in fish is linked with the practice of inadequate hygienic measure, mishandling, improper storage and use of dirty water during marketing and all unhygienic condition of the shops ${ }^{13}$.

Listeria monocytogenes, Bacillus spp. are indigenous to general environment and frequently present in fish but most of the isolates are non-pathogenic environmental strains; Salmonella spp., Staphylococcus spp. are pathogenic bacteria found in animal/ human reservoir and contamination of fish products by these bacteria is almost always due to poor hygiene (poor personal hygiene, poor processing hygiene or poor water quality $)^{19}$.

From the findings, it can be concluded that fresh and salted hilsa available in fish markets of Dhaka city may act as the carrier of potentially pathogenic bacteria which may cause food borne illness to human. Therefore, necessary hygienic steps should be followed during the salting process and in the market place as well.

\section{References}

1 Alam AKMN, Mohanty BP, Hoq ME and Thilshed S. 2012. Nutritional values, consumption and utilization of Hilsa Tenualosa ilisha (Hamilton 1822). Proc. Regional workshop on Hilsa: potential for aquaculture. 16-17 September 2012. Dhaka, Bangladesh.

2. Majumdar RK, Basu S and Anandan R. 2005. Biochemical and microbiological characteristics of salt fermented hilsa (Tenualosa ilisha). Fish Technol. 42 (1): 67-70

3. Alam AKMN. 2010. Post-harvest Loss Reduction in Fisheries in Bangladesh: A way Forward to Food Security. Final Report. NFPCSPFAO, PR\#5/08 project. Food and Agriculture Organization of the United Nations, Dhaka. 162 pp.

4. Sultana S, Abdullah-Al-Mahin and Chowdhury MAZ. 2008. Microbial load of salted hilsa (Tenualosa ilisha) and its preservation by radiation. Nucl Sci Appli. 17: 96-101

5. Eklund C and Lankford CE. 1967. Laboratory manual for general microbiology. Prentice-Hall International, Inc., London. pp. 299.

6. SAB (Society of American Bacteriologists) 1957. Manual of microbiological methods. McGraw Hill Book Company Inc., New York. pp. 315.

7. Claus GW. 1995. Understanding microbes (4 $4^{\text {th }}$ ed.), W. H. Freman and Company, New York. pp. 547.

8. Krieg NR and Holt JG. 1984. Bergey's manual of systematic bacteriology, volume 1, The Williams \& Wilkins Co., Baltimore. pp. 964 
9. Sneath PHA, Mair ME Sharpe and Holt JG. 1986. Bergey's manual of systematic bacteriology, ( (th $^{\text {ed }}$ ). Vol. 2. Williams and Wilkins Company, Baltimore. pp. 1594

10. Collins CH and Lyne PM. 1984. Microbiological methods (5 ${ }^{\text {th }}$ ed.). Butterworths and Co. Publishers Ltd. London. 448 pp.

11. WHO 1987. Manual for laboratory investigations of acute enteric infections. CDD/83.3, Rev. 1., WHO (World Health Organization), Geneva. pp. 1-109.

12. Mhlambi SG, Naidoo K and Lindsay D. 2010. Enterotoxin-producing Staphylococcus strains associated with South African Biltong at point of sale. J. Food Safety. 30: 307-317.

13. Mahin AA, Sorrowar MG, Hasan MZ, Haque MM and Harun-OrRashid. 2011. Effect of Low Temperature, Radiation and their Combination Treatments on Microorganisms Associated with Fresh Water Mola Fish, Amblypharyngodon mola (Hamilton-Buchanan 1822). Asian J Biotech. 3: 507-518.
14. Perez-Villarreal B and Pozo A. 1992. Ripening of the salted anchovy (Engraulis encrasicolus) study of the sensory, biochemical and microbiological aspects. In Quality assurance in the fish industry (Huss SS, M Jakobsen and J Liston Eds) Elsvier science publishers, Amsterdam, pp 157-167

15. Huss HH. 1995. Quality and Quality changes in fresh Fish. FAO fisheries technical paper 348, FAO, United Nations, Rome. 48pp

16. Huss HH. 1994. Assurance of seafood Quality. FAO fisheries technical paper 334, FAO, United Nations, Rome. 169 pp

17. Natarajan R, Rama and Ramesh S. 1985. Salmonella in marine food products- a review. In: Harvest and Post-harvest Technology of Fish. Society of Fisheries Technologists (India), pp: 658.

18. Shamsuzzaman MM, Mazumder SK, Siddique MA and Miah MNU. 2011. Microbial quality of hilsa shad (Tenualosa ilisha) at different stages of processing. J. Bangladesh Agril. Univ. 9 (2): 339-344,

19. Huss HH, Ababouch L and Gram L. 2004. Assessment and management of seafood safety and quality. FAO Fisheries technical paper 444. pp 53. 